\title{
Ethics of publication, between forgery, retraction and protecting freedom: an ENJOY score for authors and editors
}

\author{
Giorgina Barbara Piccoli ${ }^{1,2}$ (C)
}

Received: 22 August 2019 / Accepted: 31 August 2019 / Published online: 17 September 2019

(C) Italian Society of Nephrology 2019

Keywords Publication · Ethics · Transplantation · Istanbul declaration · Forgery

The number of retractions and expressions of concern in high-impact medical journals is steadily increasing. A dedicated retraction database has been created [1]. The studies and editorials published on retraction in different medical fields have led to this problem becoming news [2-4]. Compromised or fake peer reviews, forgery, plagiarism, non-compliance with ethical declarations, and inappropriate authorship are the most common examples, while bona fide errors account for a minority of cases [2, 3]. Predatory journals flourish and add to the confusion.

Physicians are not alone, and stories of fake news and falsifications in science are widespread: fossil birds and the controversial "memory of water" research are good examples of the fine line that divides sincere from counterfeit and the role played by economic issues [5, 6].

These last years have seen several waves of retractions, the most recent and important one regarding papers from China on transplanted organs, when it appeared that the organs had come from prisoners whose death sentence had been timed to coincide with demand; Iranian teams are also frequently cited in retraction affairs [4, 7]. In both cases, the political authorities were involved: military hospitals and prisons in the China affair, and on a lesser, but still disturbing scale, the fact that political authorities were included as authors of the Iranian papers.

China has been accused of systematic organ harvesting from political prisoners, mainly Falun Gong practitioners, whose mean age is between 20 and 30 . The scandal has received attention in both medical journals and non-scientific

Giorgina Barbara Piccoli

gbpiccoli@yahoo.it

1 Department of Clinical and Biological Sciences, University of Torino, Torino, Italy

2 Nephrologie, Centre Hospitalier Le Mans, Le Mans, France newspapers, such as The Guardian, The Independent and The New York Post [8]. These newspapers are however exceptions and the generalized silence of the media is surprising. Is it motivated by respect for patients waiting for a kidney graft in our countries who could be psychologically hurt by such news, or is it due to reluctance to share disturbing information that points to the involvement of economic interests?

The issue is not new, but the recent alert came from a scoping review published earlier this year, which succeeded in its aim of obliging all the major nephrology journals to take a position, at least with respect to previously published papers $[7,8]$. The conclusions of the study are clear: reviewers, editors and publishers were guilty of lack of attention. Researchers and clinicians who cite and use this research implicitly accept organ procurement from executed prisoners. Immediate retraction is therefore demanded [7]. The review succeeded where the media had not; in fact you will probably be surprised, as I was, by the quantity of information available on the web, including a BBC podcast, long and detailed documentaries and official reports.

I admit that I was guilty of lack of attention.

Moving from the realization of having been superficial, to my professional role of clinical researcher and journal editor, I see that several questions remain open. As authors, to what extent should we ascertain that each paper we cite meets the ethical requirements of informed consent, compliance with the Helsinki principles and, when transplantation is involved, with the Istanbul declaration? How much care must we exercise in checking that a study's methods have been ethical and, in cases of doubt, demand the raw data? Can we be satisfied with generic statements or is more required of us? In fact, as the BMJ open review specifies, many papers declare compliance with principles that were clearly not respected. Is checking compliance with ethical 
procedures the role of the author who cites a study, or is it the responsibility of the editor who publishes it?

It is difficult to say. Each of us shares responsibility, each of us is involved: author, reviewer, editor, reader. Each should ... do what? Denounce frauds, reject papers and ban their authors? The limits of our actions are once more difficult to define, and the discussion shifts from technical appraisal to a wider context. For example, should an author listed along with others in a forged paper be considered fully responsible and be "tagged" as unreliable in as many medical journals as possible? Should only the first and senior authors be penalized?

Authors of papers with falsified data are usually considered unreliable regardless of the subject dealt with. But how should authors who wrote statistically flawless papers on transplantation from executed prisoners be treated? Should all forms of lack of compliance with standards be stigmatized in the same way, or should we be more tolerant with those who accept a criminal origin of the organs they transplant, but do not falsify numbers?

While it is increasingly clear that the editors of scientific journals must thoroughly and critically examine what they publish, the balance between becoming suspicious sciencepolicemen, or blindly trusting our colleagues will not be achieved by adding one more box to tick during the submission procedure, nor by making an already time-consuming and sometimes frustrating pathway of technical steps more rigid.

An unbending, highly controlled system will probably discourage young scholars rather than well-organized counterfeiters or unethical interest groups. Just as hackers can find flaws in any system, smart fakers and criminals will sooner or later find ways to dupe the scientific community.

The issue should perhaps be treated with the same attention and caution that we use when treating our patients. Care, good will, tolerance and curiosity are a part of our clinical skills and they can be part of our reasoning as editors, while maintaining awareness that errors are made. If not, we risk losing sight of what we are doing and dedicating more time to the hidden evils than that to the joys of science.

Besides this, there are reasons, albeit not justifications, for all we do.

The forces behind the phenomenon of unethical publication, forgery and retractions are many; personal choices, desire of power, economic incentives and political pressures play different roles.

"Publish or perish" was the expression indicating the tremendous pressure that especially Northern American research settings put on individual researchers: salaries, positions and careers depended upon publication results, often measured on a short term scale. Publish or perish had its victims, but they were often isolated and psychologically fragile.
Illegal systems and criminal activities kill in different ways. A fragile individual may become the prisoner of a monstrous machine, and be unable to escape; strong-willed, intelligent and ambitious individuals may play along with an immoral system to further their careers. Power, money and prestige can push people do ruthless things.

As scientists we should condemn whatever contrasts with the principles of our profession; as physicians, we can leave a place for pity. As authors and editors, we know we will never find every mistake.

However, there may be hope: "the joy of science", to cite Anita Aperia, a Swedish nephrology pioneer [9].

Writing a medical paper implies putting together experience and progress. It demands novelty, intrinsically linked with intellectual freedom, and it should allow medicine to progress, albeit by a small step. It should be a source of happiness.

Recovering this happiness, protecting this intellectual freedom, and focusing on what really counts may be the best response to dishonesty, abuses, and crime.

One could argue that no score measures happiness. This is why we are now proposing a short ENJOY score for authors and editors (Tables 1,2).

\section{Validation of the author's score}

\section{Case A}

Imagine you wrote a paper putting all your knowledge into it. It includes pieces of your soul. You got a score of 10. You are full of hope. We reject your paper. But you are aware of the fact that $80-90 \%$ of papers are rejected by most journals, and you do not think that $80-90 \%$ of your colleagues are idiots, so you do not feel particularly stupid. You read the criticisms, you put the paper together again, and try again, since you like your paper, but you are aware that it is not perfect, and you do it over and over again ... the day it is accepted (because if you kept at it conscientiously, it will be accepted) you'll send it to all of your friends and you will go out to have good food and good wine, and be happy.

As editors, we'll never regret publishing your paper, even if it is never cited.

\section{Case B}

Imagine that you wrote an interesting paper stretching data dealing with kidney transplantation; organs come from executed prisoners of a persecuted, religious faith. You declared your paper was in accordance with Istanbul declaration. Noone objected. You should probably score less than 5 . Then you should not submit your paper to our journal. 
Table 1 ENJOY score: author self-evaluation

ENJOY score. Author self-evaluation

1. Did you ENJOY writing your paper?

Was it fun?

Well, fun may not be the best word, since diseases are seldom "fun". Let's put it differently: did your paper give you a feeling similar to going out with friends, enjoying good food and wine and discussing important issues?

2. Did you learn something from writing your paper

Well, learning means that you did not know something and when your realized this instead of saying "hell" you said "wow"

3. Was your paper a challenge?

Do you anticipate feeling excited when you press the last "OK" for submission?

4. Are you proud of your paper?

Do you want to share it with your family or best friends?

5. Are you already thinking about the next step you're going to take?

Was writing your paper as interesting as reading a book by an unknown author and wishing they had written more book? Will you be searching the Amazon site tonight to find out?

Score: 10: please, submit to our journal

Scores 5-9: go out with your friends, and think about having a nice week-end without Internet and doing something you'd like to that you might not be able to afford or have time for. Consider submitting to our journal immediately afterwards. You'll be welcomed

Scores 0-4: take a long vacation in a remote location and remain off-line. Consider joining a meditation group. An analyst is waiting for you.

Please submit to another journal

If you do not know what to say, since you did not write or read the paper and just checked your name and affiliation, then you know the answer; please ask yourself what you are doing here
0 . It did not remotely resemble going out with friends

1. Maybe with people I know, and somehow like. The food was okay

but the wine wasn't great

2. Yes, it was like being with good friends. Food and wine excellent

0 . Nothing made me say either hell or wow

1. To be polite, I said "what the hell". Definitely wasn't wowed

2. At least once I said "wow, what a smart thought this guy/gal had"

0 . No, one of my PhD students makes the submission

1. This is my third choice. I just hope it's finally accepted

2. Well, fingers crossed, my grandmother used to say that...

0 . No point. They'll only be bored

1. Yes with my Ph.D.s students

2. Yes, with all of them-children, parents, brothers, sisters, companion

0 . No thanks, I finished the book, I enjoyed it. That's it

1. This was the final step, at least for now. I enjoyed the book, now I need to rest

2. I spent $2 \mathrm{~h}$ looking for their new books and ordered them all

Table 2 ENJOY score: editor self-evaluation

ENJOY score. Editor self-evaluation

1. Did you ENJOY reading this paper?

Did this paper give you a feeling of reading a good book?

2. Did you learn something reading this paper?

Well, learning means that you did not know something and when your realized this instead of saying "hell" you said "wow"

3. Will this paper be a challenge?

Do you anticipate that this paper will arouse mixed feelings and elicit reactions?

4. Are you proud of this paper?

Do you want to share it with your friends/colleagues?

5. Are you already waiting for another paper of this kind?

Was reading this paper as interesting as reading a book by an unknown author and wishing they had written more books? Will you be searching the Amazon site tonight to find out?

Scores: 10: too good to be true

Scores: 5-9: good job, nobody is perfect

Scores 0-4: do you really enjoy being editor of this journal?
0 . Not really, but it was a large cohort/a well-known author/a powerful team

1. Yes, like the books I read before going to sleep

2. Yes, like the last book I started reading on the train, kept reading in the taxi and finished in the bathtub

0 . Nothing made me say either hell or wow

1. To be polite, I said "what the hell" Definitely wasn't wowed

2. At least once I said "wow, what a smart thought this guy/gal had"

0 . Everybody will like it; it will be widely cited and acclaimed

1. It's a good paper and might be discussed

2. It's something new, a different way of seeing things and not everybody will like it

0 . No point. They'll only be bored

1. Yes with my PhDs students

2. Yes, with all the people I work with

0 . No thanks, I finished the book, I enjoyed it. That's it

1. This was the final step, at least for now. I enjoyed the book, now need to rest

2. I spent $2 \mathrm{~h}$ looking for their new books and ordered them all 
But the ego plays strange tricks. If you are ready to share it with your best friends, to say that you learnt from it, that you are proud of your achievement, and that you would proudly share it with your son or daughter (because our journal has a great impact factor and this will be great for your career and earnings), and that you are ready to write a new one (for the above reason), then, sorry to say, we cannot do anything for you. You'll never be happy; you'll never be a decent physician or person. We'll probably trust you, and publish your paper. But your paper will be absolutely useless, since, albeit slowly, science progresses, and forgers and bad physicians are forgotten (even if not always forgiven). Our impact factor may even rise in the nest two years, but you'll have no impact on science.

As editors, we'll always regret publishing your paper, even if it is often cited and praised.

\section{Validation of the Editor score}

\section{Case A}

You got a score of 10. This is not possible. Have a cup of coffee.

\section{Case B}

You got a score of 8 . You enjoyed this paper; it's new, it's interesting. The group submitting it is not well known, yet you analyzed their methods and they looked good. You decided to take a chance. You remembered that when you were in your 30s you dreamed of publishing a paper like this one and you smile. The idea is somehow the opposite of the one advanced by some big-name professor. You smile again and turn to your next task.

\section{Case C}

You scored 4. You cannot avoid publishing this paper, i.e. your journal cannot be seen as snubbing the academic community of an emerging country. The donors' age was considered too low by one of the reviewers; however, the authors declared that they complied with the Helsinki and Istanbul declarations. It is not your business: once they sign their statements it's their responsibility. You think that it's up to others to judge, and that you are just an editor. You take an Omeprazole and go on to your next task.

\section{Compliance with ethical standards}

Conflict of interest The author declare that she has no competing interests.

Ethical approval This article does not contain any study with human participants.

\section{References}

1. http://retractiondatabase.org/RetractionSearch.aspx? Accessed 25 July 2019

2. Ferguson C, Marcus A, Oransky I (2014) Publishing: the peerreview scam. Nature 515(7528):480-482

3. Moylan EC, Kowalczuk MK (2016) Why articles are retracted: a retrospective cross-sectional study of retraction notices at BioMed Central. BMJ Open 6(11):e012047

4. https://www.nature.com/news/publisher-pulls-58-articles-by-irani an-scientists-over-authorship-manipulation-1.20916. Accessed 25 July 2019

5. Dalton R (2000) Fake bird fossil highlights the problem of illegal trading. Nature 404(6779):696

6. https://www.nature.com/news/2004/041004/full/news041004-19. html. Accessed 25 July 2019

7. Rogers W, Robertson MP, Ballantyne A, Blakely B, Catsanos R, Clay-Williams R, Fiatarone Singh M (2019) Compliance with ethical standards in the reporting of donor sources and ethics review in peer-reviewed publications involving organ transplantation in China: a scoping review. BMJ Open 9(2):e024473. https://doi. org/10.1136/bmjopen-2018-024473

8. https://www.theguardian.com/science/2019/feb/06/call-for-retra ction-of-400-scientific-papers-amid-fears-organs-came-fromchinese-prisoners. Accessed 25 July 2019

9. https://vimeo.com/201633844. Accessed 25 July 2019

Publisher's Note Springer Nature remains neutral with regard to jurisdictional claims in published maps and institutional affiliations. 